\title{
Evaluation of the Inverse Fluidized Bed Biological Reactor for Treating High-Strength Industrial Wastewaters
}

\author{
Włodzimierz Sokól, Belay Woldeyes \\ Department of Chemical Engineering, Addis Ababa University, Addis Ababa, Ethiopia \\ E-mail: \{sokolwlodzimierz, belay.160\}@yahoo.com \\ Recieved July 7, 2011; revised September 16, 2011; accepted September 22, 2011
}

\begin{abstract}
The aim of this work was to investigate the aerobic degradation of high-strength industrial (refinery) wastewaters in the inverse fluidized bed biological reactor, in which polypropylene particles of density $910 \mathrm{~kg} / \mathrm{m}^{3}$ were fluidized by an upward flow of gas through a bed. Measurements of chemical oxygen demand (COD) versus residence time $t$ were performed for various ratios of settled bed volume to reactor volume $\left(V_{b} / V_{R}\right)$ and air velocities $u$. The largest COD reduction, namely, from 54,840 to $2190 \mathrm{mg} / 1$, i.e. a $96 \%$ COD decrease, was achieved when the reactor was operated at the ratio $\left(V_{b} / V_{R}\right)=0.55$, air velocity $\mathrm{u}=0.046 \mathrm{~m} / \mathrm{s}$ and $t=65 \mathrm{~h}$. Thus, these values of $\left(V_{b} / V_{R}\right), \mathrm{u}$ and $\mathrm{t}$ can be considered as the optimal operating parameters for a reactor when used in treatment of high-strength refinery wastewaters. In the treatment operation conducted in a reactor optimally controlled at $\left(V_{b} / V_{R}\right)=0.55, u=0.046 \mathrm{~m} / \mathrm{s}$ and $t=65 \mathrm{~h}$, the conversions obtained for all phenolic constituents of the wastewater were larger than $95 \%$. The conversions of about $90 \%$ were attained for other hydrocarbons.
\end{abstract}

Keywords: Biological Wastewater Treatment, Aerobic Wastewater Treatment, High-Strength Industrial Wastewaters, Inverse Biological Reactor, Fluidized Bed Bioreactor, Low-Density Biomass Support

\section{Introduction}

The application of a fluidized bed technology to biological wastewater treatment has brought a remarkable breaktrough. The technology owes its high-rate success to much higher surface area and biomass concentration than those that can be achieved in the conventional treatment processes. A fluidized bed biological reactor (FBBR) has attracted considerable interest as an alternative to the conventional suspended growth and fixed-film wastewater treatment processes due to its high efficiency performance.

Treatment of industrial wastewaters requires a great deal of space when using systems based on activated sludge in which the retention time is many days [1]. On the other hand, a FBBR is capable of achieving treatment in low retention time because of the high biomass concentrations that can be achieved in the apparatus $[2,3]$.

Among the compounds of refinery wastewaters that are the greatest biohazards to the environment are phenols (monohydric and polyhydric), derivatized phenols, polycyclic organics (polynuclear aromatic hydrocarbons), thiocyanates, ammonia and cyanides [4].

A three-phase (gas-liquid-solid) FBBR has been successfully applied in aerobic biological treatment of industrial and municipal wastewaters [5-8]. The reactor outperforms other reactor configurations used in wastewater treatment such as the activated sludge system and packed-bed (or trickling-filter) reactor [9-12]. The superior performance of the FBBR stems from the very high biomass concentration (up to $30-40 \mathrm{~kg} / \mathrm{m}^{3}$ ) that can be achieved due to immobilisation of cells onto or into the solid particles.

However, the excessive growth of biomass on support media can lead to the channelling of bioparticles (support particles covered by biomass) in fluidized bed since the biomass loading can increase to such an extent that the bioparticles began to be carried over from a reactor. The application of a low density (matrix particle density smaller than that of liquid) biomass support in a reactor allows the control of biomass loading and provides the high oxygen concentration in the reacting liquid media $[2,13]$.

In a FBBR containing low-density particles, fluidiza- 
tion can be conducted either by an upward co-current flow of gas and liquid through a bed (Figure 1) [2,3] or by a downward flow of liquid and countercurrent upward flow of gas $[5,14]$. In the former, fluidization is achieved by an upward flow of gas whereby the gas bubbles make the bed expanding downwards into the less dense mixture of gas and liquid. In the latter, the bed is fluidized by a downward flow of a liquid counter to the net buoyancy force of the particles. Such type of fluidization is termed the inverse fluidization.

Sokół and Halfani [13] have reported that a steadystate biomass loading was obtained in a FBBR, in which polypropylene particles of density $910 \mathrm{~kg} / \mathrm{m}^{3}$ were fluidized by an upward co-current flow of gas and liquid. Karamanev et al. [14] have achieved a constant biomass loading in a FFBR, in which low density particles were fluidized by downflow of the liquid. Rusten et al. [15] have demonstrated that a steady-state biomass loading was attained in a FFBR containing low-density particles made of polyethylene.

The aim of this work was to investigate the aerobic degradation of high strength wastewaters in a FFBR, in which polypropylene particles of density $910 \mathrm{~kg} / \mathrm{m}^{3}$ were fluidized by an upward flow of gas through a bed. Experiments on COD reduction were performed for various ratios of settled bed volume to reactor volume $\left(V_{b} / V_{R}\right)$, air velocities $u$ and residence times $t$.

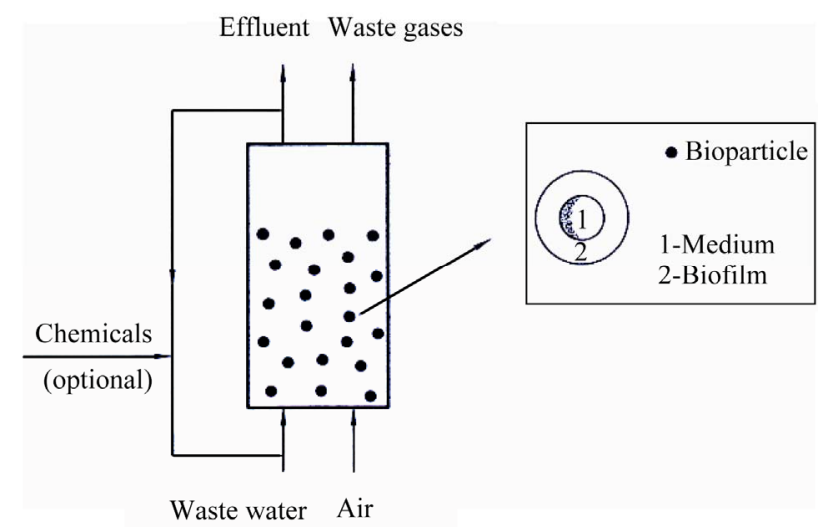

Figure 1. Scheme of the inverse fluidized bed biological reactor.

\section{Experimentation}

\subsection{Experimental Set-up}

Experiments were conducted in the reactor shown in Figure 2. A growing medium, stored in a reservoir 1, was pumped into the bottom of the reactor by a centrifugal pump 5. Before entering the bed, the liquid was mixed with air by means of a sparger. The air was introduced to the bed through a distributor 7 whose plate had 200 holes of $4 \mathrm{~mm}$ diameter on a triangular pitch.

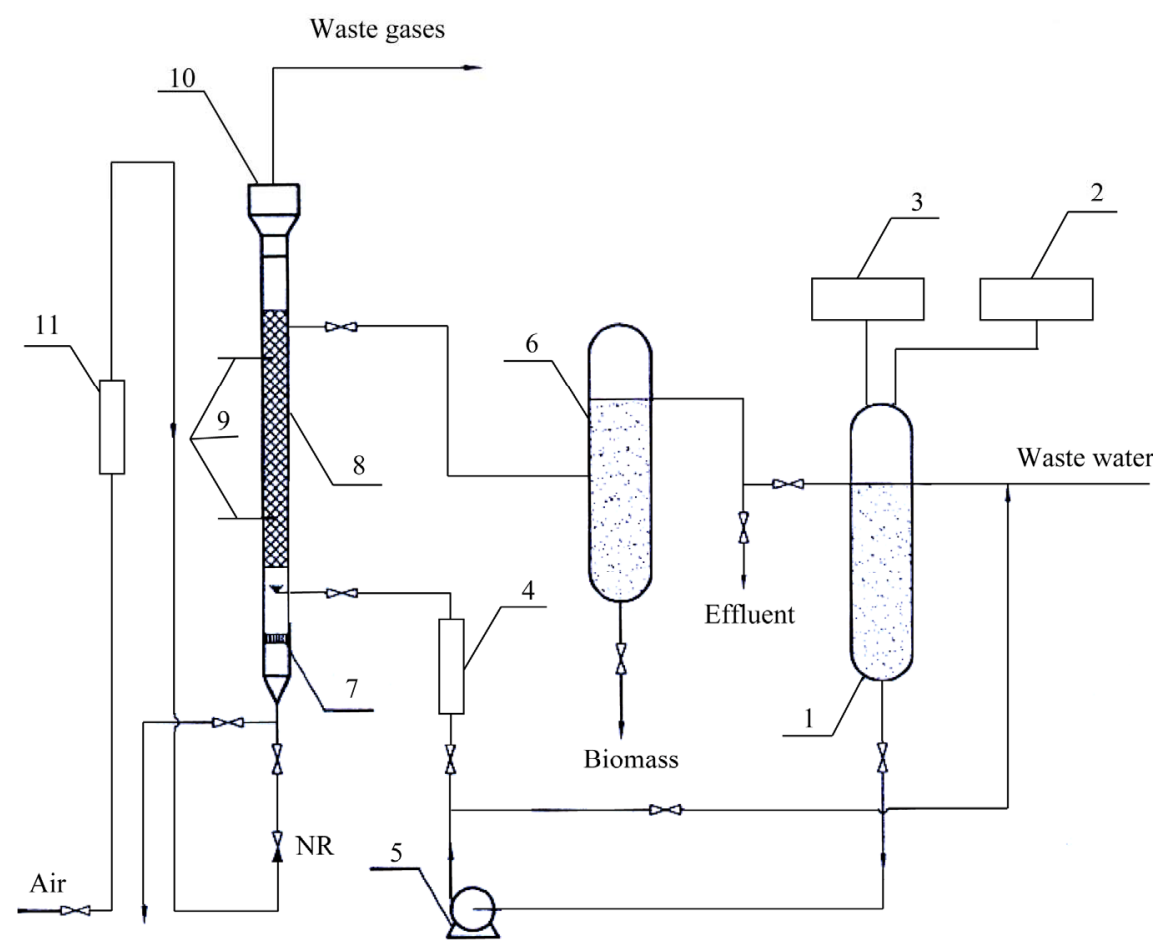

Figure 2. Schematic diagram of the experimental apparatus: 1, reservoir; 2 , temperature control system; 3, pH control system; 4, liquid rotameter; 5, pump; 6, intermediate reservoir; 7, air distributor; 8, sampling; 9, fluidized section; 10, disengaging section; 11, air rotameter. 
The fluidised bed section 9, made of Duran glass, had a $20 \mathrm{~cm}$ internal diameter and was $6 \mathrm{~m}$ high. It was ended by a disengaging cap 10 with a $60 \mathrm{~cm}$ internal diameter and a height of $80 \mathrm{~cm}$. The biomass sloughed off from the particles was separated from the effluent in a vessel 6 and removed from the system. The flow rate of the liquid was measured by a rotameter 4 and controlled by a ball valve. The air flow rate was measured using a rotameter 11 and controlled by a needle valve. The $\mathrm{pH}$ was adjusted by a control system 3, consisting of a pH-meter and micro-pumps supplying base or acid; as required. The temperature control system 2 consisted of a coil with cold water and an electric heater coupled with a contact thermometer.

The biomass support was the polypropylene particles of density $910 \mathrm{~kg} / \mathrm{m}^{3}$ whose dimensions are given in Figure 3.

\subsection{Feed and Microorganisms}

The growing medium was the wastewater whose composition is given in Table 1. The wastewater was enriched in mineral salts by adding the following $(\mathrm{mg} / \mathrm{l})$ : $\left(\mathrm{NH}_{4}\right)_{2} \mathrm{SO}_{4}: 500 ; \mathrm{KH}_{2} \mathrm{PO}_{4}: 200 ; \mathrm{MgCl}_{2}: 30 ; \mathrm{NaCl}: 30$; $\mathrm{CaCl}_{2}: 20$; and $\mathrm{FeCl}_{3}: 7$ [1].

The inoculum was the activated sludge taken from the biological treatment unit operated at the refinery from which wastewater was used in this research.

\subsection{Methodology}

Sokó and Korpal [1] have established that the optimal ratio $\left(V_{b} / V_{R}\right)$ for a FBBR when used in biological wastewater treatment was equal to 0.55 . Therefore, in this study experiments were performed for the ratios $\left(V_{b} / V_{R}\right)$ equal to $0.50,0.55$ and 0.60 . This was to cover the searched range of $\left(V_{b} / V_{R}\right)$ from 0.50 to 0.60 in step 0.05 which is sufficient accuracy for industrial practice.

The air velocities $u$ applied in experiments are given in Figures 4-6.

\subsubsection{Biomass Culturing}

The particles and the growing medium were introduced into the reactor to give a ratio $\left(V_{b} / V_{R}\right)=0.50$. To start growth of the microorganisms on the particles, a batch culture was first initiated by introducing about 151 of the inoculum into the reactor. Then the culture was incubated for approximately $48 \mathrm{~h}$ to encourage cell growth and the adhesion of freely suspended biomass on the particles. The air was supplied at a flow rate of 0.025 $\mathrm{m}^{3} / \mathrm{s}$ and this was found to be sufficient for biomass growth $[1,2]$. The $\mathrm{pH}$ was controlled in the range 6.5 7.0 and the temperature was maintained at $28^{\circ} \mathrm{C}-30^{\circ} \mathrm{C}$.
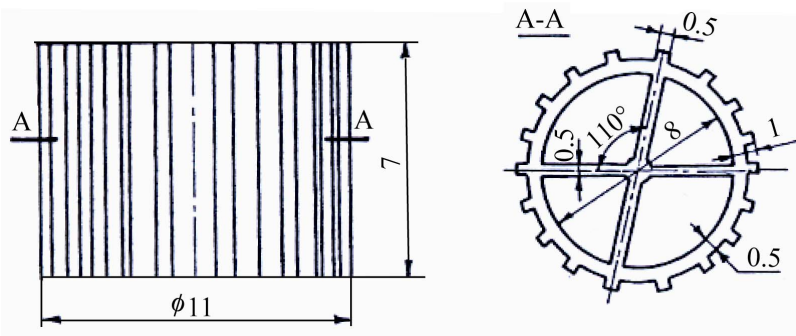

Figure 3. Dimensions (in mm) of biomass support.

Table 1. Composition of feed (wastewater) and effluent from a reactor optimally controlled at $\left(V_{b} / V_{R}\right)_{m}=0.55, u_{m}=$ $0.046 \mathrm{~m} / \mathrm{s}$ and $t=65 \mathrm{~h}$.

\begin{tabular}{lccc}
\hline Constituent & $\begin{array}{c}\text { Concentration } \\
\times 10^{3} \mathrm{mg} / \mathrm{l}\end{array}$ & & $\begin{array}{c}\text { Fractional } \\
\text { conversion }\end{array}$ \\
\hline & Feed & Effluent & \\
\hline o-Cresol & 15250 & 597.8 & 0.96 \\
m-Cresol & 8240 & 326.2 & 0.96 \\
3,5 Dimethylphenol & 7050 & 421.4 & 0.94 \\
Phenol & 5740 & 174.6 & 0.97 \\
2,4 Dimethylphenol & 4760 & 286.2 & 0.94 \\
Benzene & 3450 & 102.5 & 0.97 \\
Toluene & 2972 & 88.6 & 0.97 \\
3,4-Dimethylphenol & 2190 & 107.2 & 0.95 \\
Isopropylphenol & 2180 & 87.4 & 0.96 \\
o-Xylene & 1130 & 57.9 & 0.95 \\
2,6-Dimethylphenol & 980 & 67.3 & 0.93 \\
C -Phenyl & 240 & 16.4 & 0.93 \\
Ethylphenol & 190 & 5.6 & 0.97 \\
C 4 -Phenyl & 70 & 6.3 & 0.91 \\
\hline
\end{tabular}

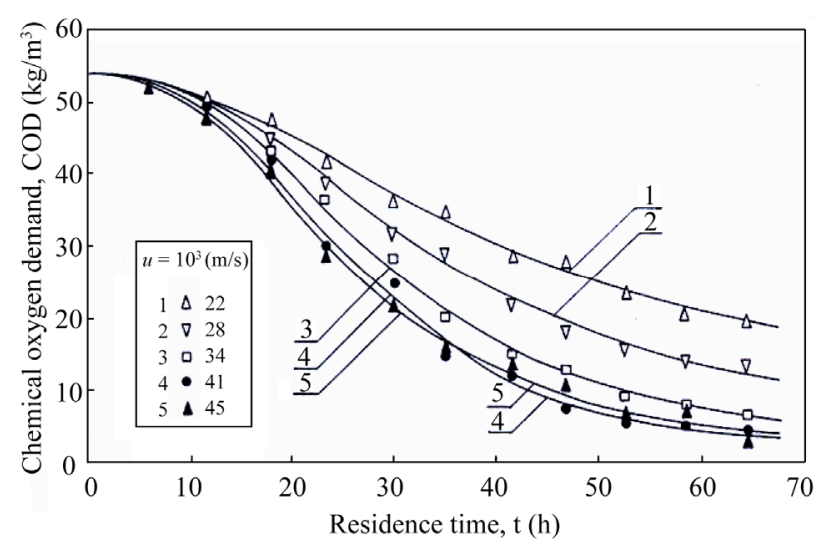

Figure 4. Relationship between chemical oxygen demand COD and residence time $t$ for ratio $\left(V_{b} / V_{R}\right)=0.50$ and various air velocities $u$.

When the biofilm had begun to grow on the particles, the growing medium was started to be pumped into the reactor at a dilution rate $D=0.15 \mathrm{~h}^{-1}$. This value of $D$ corresponded to the smallest time $t$ applied for the ratio $\left(V_{b} / V_{R}\right)=0.50(t=1 / \mathrm{D}=6.67 \mathrm{~h}$ in Figure 4). Next, the air velocity $u$ was set at the smallest value applied for the $\left(V_{b} / V_{R}\right)=0.50(u=0.022 \mathrm{~m} / \mathrm{s}$ in Figure 4) and the cultivation was continued until the constant biomass loading 
was achieved in a reactor. The occurrence of the steadystate biomass loading was established by weighting the mass of cells grown on the support. The biomass was scraped from the sample particles and dried at temperature $105^{\circ} \mathrm{C}$ for $1 \mathrm{~h}$. It was considered that the steady state occurred when the weight of biomass in two consecutive samples differed less than $5 \%$. The steady-state biomass loading was attained in a reactor after the cultivation for approximately two weeks.

\subsubsection{Treatment Operation}

When the steady-state biomass loading was achieved, a sample liquid was withdrawn from the reactor and COD was measured by the procedure recommended by Verstraete and van Vaerenbergh[16]. It was established that once the constant biomass loading occurred in a reactor, the value of COD was practically at steady state.

Next, the air velocity $u$ was increased stepwise to its next value applied for $\left(V_{b} / V_{R}\right)=0.50(u=0.028 \mathrm{~m} / \mathrm{s}$ in Figure 4) and the cultivation was continued until the new steady-state biomass loading was obtained. When this was attained, a value of COD was measured by the method mentioned earlier [16]. These experiments for $\left(V_{b} / V_{R}\right)=0.50$ were conducted for all values of $u$ shown in Figure 4.

Then the dilution rate $\mathrm{D}$ was decreased stepwise to its next value applied for $\left(V_{b} / V_{R}\right)=0.50(t=1 / \mathrm{D}=13.34 \mathrm{~h}$ in Figure 4) and the air velocity $u$ was re-set to its smallest value applied for the $\left(V_{b} / V_{R}\right)=0.50(u=0.022$ $\mathrm{m} / \mathrm{s}$ in Figure 4). The cultivation was continued until the steady-state biomass loading was achieved. When this occurred, a value of COD was measured following the procedure mentioned earlier [16]. These experiments were conducted for all air velocities $u$ and residence times $t$ shown in Figure 4. The results of the experiments are given in Figure 4.

The above experiments were also performed for the ratios $\left(V_{b} / V_{R}\right)$ equal to 0.55 and 0.60 . In order to get the ratio $\left(V_{b} / V_{R}\right)=0.55$, an adequate volume of biomass-free particles was added to a reactor at the end of experimenttation for $\left(V_{b} / V_{R}\right)=0.50$. Similarly, the ratio $\left(V_{b} / V_{R}\right)=$ 0.60 was obtained by the addition of fresh particles to a reactor at the end of experimentation for $\left(V_{b} / V_{R}\right)=0.55$. The results of the experiments are shown in Figures 5 and 6.

In order to determine the largest COD removal, experiments on COD reduction were performed for those values of $u_{m}$ for which the largest COD reductions were achieved in runs shown in Figures 4-6. The results of the experiments are given in Figure 7.

It should be pointed out that the air velocities $u$ applied in the experiments were several times larger than the minimum fluidization velocity $u_{f}$. This was possible

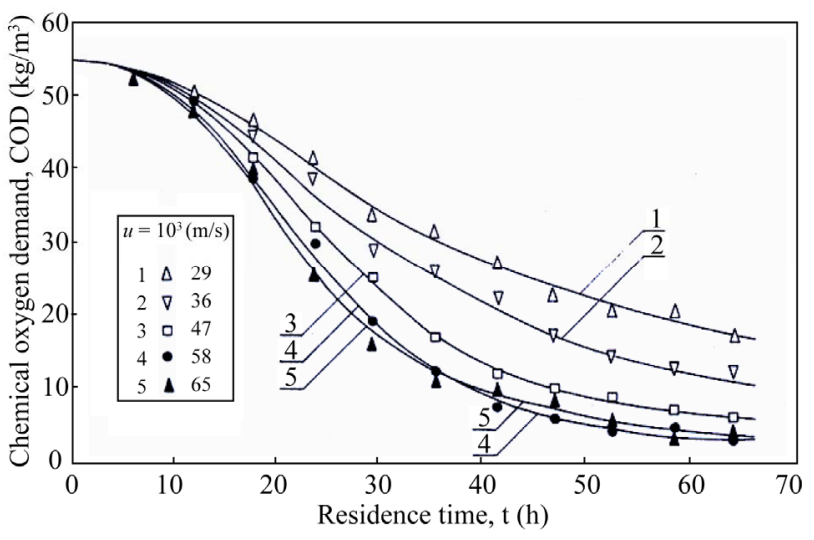

Figure 5. Dependence of chemical oxygen demand COD on residence time $t$ for ratio $\left(V_{b} / V_{R}\right)=0.55$ and various air velocities $u$.

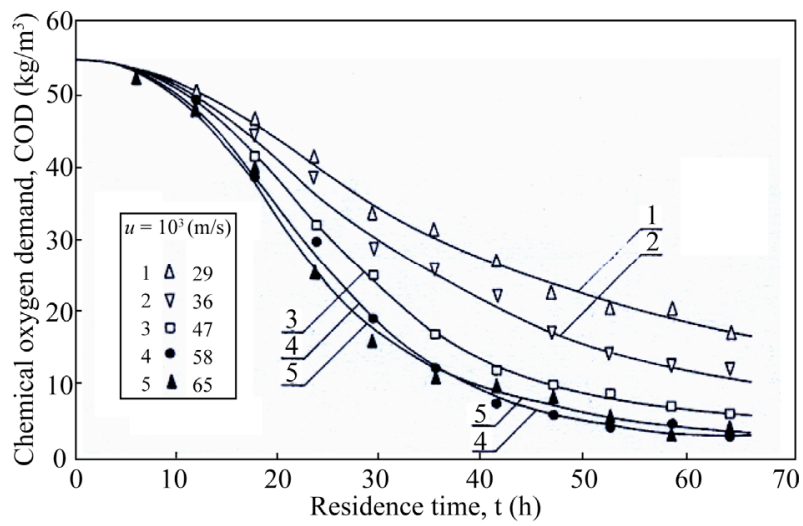

Figure 6. Relationship between chemical oxygen demand COD and residence time $t$ for ratio $\left(V_{b} / V_{R}\right)=0.60$ and various air velocities $u$.

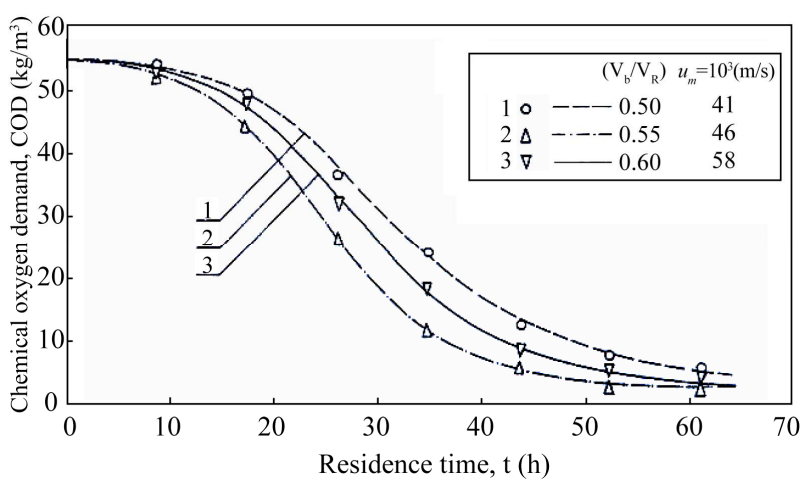

Figure 7. Dependence of chemical oxygen demand COD on residence time $t$ for treatment operation conducted in a reactor controlled at values of $\left(V_{b} / V_{R}\right)_{m}$ and $u_{m}$ for which the greatest COD removals were obtained in runs shown in Figures 4-6.

because the reactor was operated at the ratios $\left(V_{b} / V_{R}\right)$ smaller than the critical values of $\left(V_{b} / V_{R}\right)_{c r}[13]$. At the ratios $\left(V_{b} / V_{R}\right)$ equal to, or larger than, $\left(V_{b} / V_{R}\right)_{c r}$, the 
movement of the whole bed was impossible: the particles either remained at the top of the reactor or they settled at its bottom. On the other hand, the air velocities $u$ were smaller than the critical velocity $u_{c r}$ at which the entire bed settled at the reactor bottom.

Stratification of the particles coated with the biomass led to their movement to the base of the bed where concentrations of constituents of the wastewater were the highest. This was desirable since the constituents could penetrate far into the biofilm so that most of the biomass was active $[1,2]$.

\section{Results and Discussion}

It can be seen in Figures 4-6 that, for a set time $t$ and ratio $\left(V_{b} / V_{R}\right)$, a concentration of COD in effluent depended on the air velocity $u$. A reduction in COD initially increased, and then decreased with an increase in $u$. It can be noticed, for example, in Figure 4 that for a set $t$ the values of COD were decreasing with an increase in $u$ up to $0.041 \mathrm{~m} / \mathrm{s}$. The smallest value of COD was attained for $u=0.041 \mathrm{~m} / \mathrm{s}$. For the air velocities $u$ larger than $0.041 \mathrm{~m} / \mathrm{s}$, the values of COD were increasing with an increase in $u$. This can be explained by the fact that with an increase in $u$ up to $0.041 \mathrm{~m} / \mathrm{s}$, an interfacial (air-liquid) area increased, and consequently the amount of the oxygen supplied for biomass growth increased [1]. Thus, for the $u$ smaller than $0.041 \mathrm{~m} / \mathrm{s}$, oxygen was the limiting factor for biomass growth. On the other hand, for the air velocities greater than $0.041 \mathrm{~m} / \mathrm{s}$, the degradation rate of the constituents of the wastewaters was the controlling factor of the treatment process [3].

The value of $u_{m}$ for which the largest decrease in COD was obtained for a set $t$, depended on the ratio $\left(V_{b} / V_{R}\right)$, and hence on volume $V_{b}$ of the particles applied in the reactor (Figures 4-6). With increasing $V_{b}$, the value of $u_{m}$ increased. Thus, a large volume of the particles can lead to an increase in the amount of the air required for biomass growth, and consequently to an increase in the resulting energy cost [13].

It can be noted in Figures 4-6 that for set $t$ and $u$, a decrease in COD values depended on the ratio $\left(V_{b} / V_{R}\right)$. The largest reduction in COD was attained at $\left(V_{b} / V_{R}\right)=$ 0.55. An increase in COD removal with an increase in the $\left(V_{b} / V_{R}\right)$ from 0.50 to 0.55 can be attributed to the fact that for increasing $\left(V_{b} / V_{R}\right)$, more biomass grown on the particles participated in degradation of the constituents of the wastewater. On the other hand, a decrease in COD removal observed with an increase in $\left(V_{b} / V_{R}\right)$ from 0.55 to 0.60 was due to the fact that in this case, a significant volume of the reactor was occupied by the particles, and consequently the aeration characteristics of the bed had worsened [2].
It can be noticed in Figure 7 that the values of COD were practically at steady state for times $t$ greater than 65 h. The largest COD removal occurred when the reactor was operated at $\left(V_{b} / V_{R}\right)_{m}=0.55$ and $u_{m}=0.046 \mathrm{~m} / \mathrm{s}$. A decrease in COD from 54,840 to $2190 \mathrm{mg} / \mathrm{l}$, that is, a $96 \%$ COD removal, was achieved when a reactor was optimally controlled at $\left(V_{b} / V_{R}\right)_{m}=0.55, u_{m}=0.046 \mathrm{~m} / \mathrm{s}$ and $t=65 \mathrm{~h}$.

The biomass loading was successfully controlled in a reactor containing low density particles used as biomass support. This was due to particle geometry and particularly availability of the internal surface and the grooves on external surface of the particles for biomass growth. With such geometry of the particles, shear forces occur ring between the particles and the liquid sloughed off excess of biomass mainly from the external, and to less extend from the internal, surface of the particles. Furthermore, the attrition, associated with particle-particle and particle-wall collisions, sloughed off biomass grown in the grooves and on the internal surface was less abrupt than the cells grown on the external surface of the particles.

In the first continuous culture, conducted at $\left(V_{b} / V_{R}\right)=$ 0.50 after switching from batch to continuous culture, the steady-state biomass loading was achieved after cultureing for about 12 days. In the continuous cultures performed after change in $\left(V_{b} / V_{R}\right)$ at a set $u$, the constant mass of cells grown on the support media was achieved after approximately 6 days of operation. With change in $u$ at a set $\left(V_{b} / V_{R}\right)$, the new steady-state biomass loading occurred after the culturing for about 4 days.

\section{Conclusions}

The largest COD decrease, namely, from 54,840 to 2190 $\mathrm{mg} / \mathrm{l}$, i.e. a $96 \% \mathrm{COD}$ reduction, was achieved when the reactor was operated at the ratio $\left(V_{b} / V_{R}\right)=0.55$, air velocity $u=0.046 \mathrm{~m} / \mathrm{s}$ and $t=65 \mathrm{~h}$. Thus, these values of $\left(V_{b} / V_{R}\right), u$ and $t$ can be considered as the optimal operating parameters for a reactor when used in treatment of high-strength refinery wastewaters.

In the treatment operation conducted in a reactor optimally controlled at $\left(V_{b} / V_{R}\right)=0.55, u=0.046 \mathrm{~m} / \mathrm{s}$ and $t$ $=65 \mathrm{~h}$, the conversions obtained for all phenolic constituents of the wastewater were larger than $95 \%$. The conversions of about $90 \%$ were attained for other hydrocarbons.

\section{References}

[1] W. Sokół and W. Korpal, "Aerobic Treatment of Wastewaters in the Inverse Fluidised Bed Biofilm Reactor," Chemical Engineering Journal, Vol. 118, No. 3, 2006, pp. 199-205. doi:10.1016/j.cej.2005.11.013 
[2] W. Sokół, “Operational Range for a Gas-Liquid-Solid Fluidized Bed Aerobic Biofilm Reactor with a LowDensity Biomass Support," International Journal of Chemical Reaction Engineering, Vol. 8, 2010, Article ID: A111. http://www.bepress.com/ijcre/vol8/A111

[3] W. Sokół, A. Ambaw and B. Woldeyes, "Biological Wastewater Treatment in the Inverse Fluidised Bed Reactor," Chemical Engineering Journal, Vol. 150, No. 1, 2009, pp. 63-68. doi:10.1016/j.cej.2008.12.021

[4] P. Hüppe, H. Hoke and D. C. Hempel, "Biological Treatment of Effluents from a Coal Tar Refinery Using Immobilized Biomass," Chemical Engineering Technology, Vol. 13, No. 1, 1990, pp. 73-79.

doi:10.1002/ceat.270130110

[5] A. Alvarado-Lassman, E. Rustrian, M. A. Garcia-Alvarado, G. C. Rodriguez-Jimenez and E. Houbron, "Brewery Wastewater Treatment Using Anaerobic Inverse Fluidized Bed Reactors," Bioresource Technology, Vol. 99, 2008, pp. 3009-3015. doi:10.1016/j.biortech.2007.06.022

[6] M. Bajaj, C. Gallert and J. Winter, "Biodegradation of High Phenol Containing Synthetic Wastewater by an Aerobic Fixed Bed Reactor," Bioresource Technology, Vol. 99, No. 17, 2008, pp. 8376-8381. doi:10.1016/j.biortech.2008.02.057

[7] A. Lohi, M. Aivarez-Cuenca, G. Anania, S. R. Upreti and L. Wan, "Biodegradation of Diesel Fuel-Contaminated Wastewater Using a Three-Phase Fluidized Bed Reactor," Journal of Hazardous Materials, Vol. 154, No. 1-3, 2008, pp. 105-111. doi:10.1016/j.jhazmat.2007.10.001

[8] M. Rajasimman and C. Karthikeyan, "Aerobic Digestion of Starch Wastewater in a Fluidized Bed Bioreactor with Low Density Biomass Support," Journal of Hazardous Materials, Vol. 143, No. 1-2, 2007, pp. 82-86. doi:10.1016/j.jhazmat.2006.08.071

[9] N. Fernandez, S. Montalvo, R. Borja, L. Guerrero, E. Sanchez, I. Cortes, M. F. Comenarejo, L. Traviso and F. Raposo, "Performance Evaluation of an Anaerobic Flu- idized Bed Reactor with Natural Zeolite as Support Material When Treating High-Strength Distillery Wastewater," Renewable Energy, Vol. 33, No. 11, 2008, pp. 2458 2466. doi:10.1016/j.renene.2008.02.002

[10] P. A. Fitzgerald, "Comprehensive Monitoring of a Fluidized Bed Reactor for Anaerobic Treatment of High Strength Wastewater," Chemical Engineering Science, Vol. 51, No. 11, 1996, pp. 2829-2834. doi:10.1016/0009-2509(96)00160-1

[11] R. Sowmeyan and G. Swaminathan, "Evaluation of Inverse Anaerobic Fluidized Bed Reactor for Treating High Strength Organic Wastewater," Bioresource Technology, Vol. 99, No. 9, 2008, pp. 3877-3880. doi:10.1016/j.biortech.2007.08.021

[12] R. Sowmeyan and G. Swaminathan, "Performance of Inverse Anaerobic Fluidized Bed Reactor for Treating High Strength Organic Wastewater during Start-Up Phase," Bioresource Technology, Vol. 99, No. 14, 2008, pp. 62806284. doi:10.1016/j.biortech.2007.12.001

[13] W. Sokół and M. R. Halfani, "Hydrodynamics of a Gas-Liquid-Solid Fluidized Bed Bioreactor with a Low Density Biomass Support," Biochemical Engineering Journal, Vol. 3, No. 3, 1999, pp. 185-192. doi:10.1016/S1369-703X(99)00016-9

[14] D. G. Karamanev, T. Nagamune and K. Endo, "Hydrodynamics and Mass Transfer Study of a Gas-Liquid-Solid Draft Tube Spouted Bed Bioreactor," Chemical Engineering Science, Vol. 47, No. 13-14, 1992, pp. 35813588. doi:10.1016/0009-2509(92)85073-K

[15] B. Rusten, H. Odegaard and A. Lundar, "Aerobic Treatment of Wastewaters in a Novel Biological Reactor," Water Science and Technology, Vol. 26, 1992, pp. 703708.

[16] W. Verstraete and E. van Vaerenbergh, "Aerobic Activated Sludge," In: W. Schonborn, Ed., Biotechnology, Vol. 8, VCH Verlagessellschaft mbH, Weinheim, 1986, pp. 43-112.

\section{Notation}

$\begin{array}{ll}\text { COD } & \text { Chemical oxygen demand }\left(\mathrm{kg} / \mathrm{m}^{3}\right) \\ \mathrm{D} & \text { Dilution rate }\left(\mathrm{h}^{-1}\right) \\ t & \text { Mean residence time }(\mathrm{h}) \\ u & \text { Superficial upflow air velocity }(\mathrm{m} / \mathrm{s}) \\ u_{f} & \text { Minimum fluidization air velocity }(\mathrm{m} / \mathrm{s})\end{array}$

$u_{c r} \quad$ Critical air velocity $(\mathrm{m} / \mathrm{s})$

$V_{b} \quad$ Volume of settled bed $\left(\mathrm{m}^{3}\right)$

$V_{R} \quad$ Reactor volume $\left(\mathrm{m}^{3}\right)$

\section{Subscript}

$m$ denotes values giving the greatest COD reduction 